DOI : 10.29408/jit.v4i1.2961 Link : https://dx.doi.org/10.29408/jit.v4i1.2961

\title{
Analisis Perbandingan Pengaruh Pertumbuhan Ekonomi Terhadap Tingkat Kesejahteraan Masyarakat Pada Desa Suralaga Dengan Menggunakan Algoritma Naive Bayes Dan Support Vector Machine (Svm)
}

\author{
Fathurrahman ${ }^{1 *}$, Yupi Kuspandi Putra ${ }^{2}$ \\ 1,2 Program Studi Sistem Informasi, Universitas Hamzanwadi \\ fathurrahman.bloger@gmail.com
}

\begin{abstract}
Abstrak
Data merupakan sebuah benda mati yang tidak berarti dan tidak berguna untuk apapun. Pernyataan ini merupakan pernyataan yang tidak didasarkan pada fakta dan realitas yang ada. Pada prinsipnya Data merupakan sebuah benda mati yang kumpulannya dapat sangat berpengaruh dalam segala segi kehidupan manusia. Data dapat menggemparkan dunia apabila diolah dan dipublikasikan. Karena begitu besarnya pengaruh data, maka manusia dapat berbicara dengan leluasa yang kemungkinan besar tidak dapat dibantahkan. Data mampu mempengaruhi perkembangan dan kemajuan suatu bangsa dalam segala hal seperti : Perekonomian, kesehatan, kebijakan, keamanan dan lain sebagainya. Oleh sebab itu data yang diperoleh dengan cara survey dan lain sebagainya, harus diperlakukan dengan seksama agar mampu memberikan kontribusi yang maksimal dalam pengambilan keputusan. Pencarian untuk pertumbuhan ekonomi yang stabil dan lingkungan yang berkelanjutan kualitas dengan cepat menjadi isu topikal di antara pemerintah, lembaga internasional dan pemangku kepentingan lain yang tertarik pada pembangunan berkelanjutan. Nilai akurasi yang tertinggi ditunjukkan oleh eksperimen menggunakan K-Vold Validation 8 dan K-Vold Validation 10. Sedangkan toleransi yang diberikan pada K-Vold Validation $8(0.49 \%)$ lebih kecil dari K=Vold Validation 10 sebesar $(0.58 \%)$. Hal ini berarti K-Vold Validation 8 lebih ketat dari K-Vold Validation 10. Sehingga yang paling baik digunakan dalam pegambilan keputusan adalah K-Vold Validation 8 sebesar $99.62 \%$ dengan toleransi $0.49 \%$. Hasil pengolahan data menggunakan algoritma Naive Bayes dan Support Vector Machine, sama-sama memberikan gambaran bahwa pengaruh ekonomi terhadap tingkat kesejahteraan masyarakat Desa Suralaga sangat besar dan dapat diambil kesimpulan bahwa rata-rata masyarakat Desa Suralaga termasuk dalam kategori masyarakat yang tidak sejahtera. Hal ini ditunjukkan dengan masih banyaknya masyarakat yang menggantungkan hidupnya dari bekerja sebagai buruh, tenaga kerja asing.
\end{abstract}

Kata Kunci : SDGs, Naive Bayes, SVM, Ekonomi

\begin{abstract}
Data is an inanimate object that is meaningless and useless for anything. This statement is a statement that is not based on existing facts and realities. In principle, data is an inanimate object whose collection can be very influential in all aspects of human life. Data can shock the world if processed and published. Because data is so influential, humans can speak freely which is unlikely to be debated. Data is able to influence the development and progress of a nation in all respects such as: economy, health, policy, security and so on. Therefore, data obtained by means of surveys and so on, must be treated carefully in order to be able to provide maximum contribution in decision making. The search for stable economic growth and environmentally sustainable quality is fast becoming a topical issue among governments, international agencies and other stakeholders interested in sustainable development. The highest accuracy value is shown by experiments using K-Vold Validation 8 and KVold Validation 10. While the tolerance given to $K$-Vold Validation $8(0.49 \%)$ is smaller than $K=$ Vold Validation 10 of $(0.58 \%)$. This means that $K$-Vold Validation 8 is tighter than $K$-Vold Validation 10 . So that the best used in decision making is K-Vold Validation 8 at $99.62 \%$ with a tolerance of $0.49 \%$. The results of data processing using the Naive Bayes algorithm and the Support Vector Machine both illustrate that the economic influence on the
\end{abstract}


DOI : 10.29408/jit.v4i1.2961 Link : https://dx.doi.org/10.29408/jit.v4i1.2961

level of welfare of the Suralaga Village community is very large and it can be concluded that the average Suralaga Village community is included in the category of not prosperous. This is indicated by the fact that there are still many people who depend on their livelihoods from working as laborers and foreign workers.

Keywords: SDGs, Naive Bayes,SVM, Economic

\section{Pendahuluan}

Data merupakan sebuah benda mati yang tidak berarti dan tidak berguna untuk apapun. Pernyataan ini merupakan pernyataan yang tidak didasarkan pada fakta dan realitas yang ada. Pada prinsipnya data merupakan sebuah benda mati yang kumpulannya dapat sangat berpengaruh dalam segala segi kehidupan manusia. Data mampu mempengaruhi perkembangan dan kemajuan suatu bangsa dalam segala hal seperti : Perekonomian, kesehatan, kebijakan, keamanan dan lain sebagainya. Oleh sebab itu data yang diperoleh dengan cara survey dan lain sebagainya, harus diperlakukan dengan seksama agar mampu memberikan kontribusi yang maksimal dalam pengambilan keputusan. Data yang menyangkut tentang ekonomi adalah kebijakan yang digunakan oleh suatu negara untuk mengalokasikan sumber daya yang dimilikinya baik kepada individu maupun organisasi $\mathrm{di}$ negara tersebut. Dalam beberapa sistem, seorang individu boleh memiliki semua faktor produksi. Sementara dalam sistem lainnya, semua faktor tersebut di pegang oleh pemerintah. Kebanyakan sistem ekonomi di dunia berada di antara dua sistem ekstrem tersebut. Sistem ekonomi yang telah berjalan dengan baik, akan mampu menjaga kestabilan ekonomi yang pada akhirnya berimbas pada tingkat kesejahteraan masyarakat yang ada di dalamnya. Kestabilan ekonomi akan mampu menjaga tingkat kesejahteraan masyarakatnya dan apabila tingkat kesejahteraan masyarakat dapat di jaga, maka tingkat keamanan dan kenyamanan masyarakat yang ada didalam sistem itu akan terjamin. Berawal dari permasalahan tersebut, maka untuk menjawab permasalahan penelitian ini akan memberikan gambaran terhadap pemahaman tentang sejauh mana tingkat perekonomian, mampu memberikan indikasi yang jelas terhadap kesejahteraan.

\section{Tinjauan Pustaka}

\subsection{Penelitian terkait}

Untuk memperkuat penelitian ini, maka dilakukan kajian dan tinjauan terhadap penelitian-penelitian sebelumnya yang bersesuaian dengan penelitian yang dilakukan. Penelitian terdahulu yang bersesuaian dengan penelitian yang kami lakukan antara lain :

- Penelitian yang dilakukan oleh Kamran Ali Khan Niazi, dalam artikelnya yang berjudul 
DOI : 10.29408/jit.v4i1.2961 Link : https://dx.doi.org/10.29408/jit.v4i1.2961

"Hotspot diagnosis for solar photovoltaic modules using a Naive Bayes Classifier" menghasilkan bahwa pemantauan dan pemeliharaan modul fotovoltaik (PV) sangat penting untuk operasi yang andal dan efisien. Hotspot dalam modul PV karena berbagai cacat dan kondisi operasional dapat mengganggu keandalan, dan dalam giliran, seluruh sistem PV. Dari sudut pandang pemantauan, hotspot harus dideteksi dan dikategorikan perawatan selanjutnya. Hotspot yang dikategorikan dideteksi dengan melatih algoritma pembelajaran mesin, yaitu pengklasifikasian Naive Bayes (NB). Hasil eksperiment yang dilakukan pada sistem PV 42,24 kWp, yang menunjukkan bahwa tingkat pengenalan rata-rata sekitar $94,1 \%$ dicapai untuk set 375 sampel[1].

- Penelitian yang dilakukan oleh Silvina Niell dalam artikelnya yang berjudul "Beehives biomonitor pesticides in agroecosystems: Simple chemical and biological indicators evaluation using Support Vector Machines (SVM)" menghasil kesimpulan bahwa lebah secara luas dikenal sebagai biomonitor lingkungan. Namun berdasarkan indikator biaya rendah Kegiatan lebah (selain kematian) yang dapat digunakan untuk memantau status lingkungan agroekosistem belum telah dilaporkan. Indikator biologi dan kimia dievaluasi menggunakan Support Vector Machine (SVM) model. Tujuannya adalah untuk mengklasifikasikan lingkungan ke dalam kategori terpengaruh dan tidak (atau minimal) terpengaruh dengan kehadiran pestisida. Model SVM berdasarkan estimasi populasi sederhana dan area induk memberikan 57\% akurasi dalam klasifikasi. Model berdasarkan variabel dibangun menggunakan hasil analisis kimia (bilangan pestisida terdeteksi di setiap sampel; jumlah total unit beracun, terkait dengan lebah dan mamalia; dan jumlah field Environmental Impact Quotient, $E I Q$, dari setiap pestisida yang terdeteksi) memberikan akurasi 100\% dalam klasifikasi. Fakta ini dapat digunakan untuk mendapatkan indikator biologis dari berbagai lokasi dan menerapkan model SVM menunjuk kan musim dan ekosistem yang berisiko di mana indikator kimiawi lebih lanjut harus dipelajari. Sebagai variabel masukan benar-benar eksplisit dan dapat diubah atau diperbarui, pendekatan yang diikuti dalam studi ini menggunakan SVM menyediakan dasar yang stabil untuk meningkatkan pengembangan indikator untuk sistem produksi pertanian biomonitoring[2].

- Penelitian yang dilakukan oleh Korosh Mahmodi, dalam artikelnya yang berjudul 
DOI : 10.29408/jit.v4i1.2961 Link : https://dx.doi.org/10.29408/jit.v4i1.2961

"Detection and classification of dieselbiodiesel blends by LDA, QDA and SVM approaches using an electronic nose" membahas tentang deteksi dan klasifikasi biodiesel dari berbagai sumber menggunakan electronic nose melalui penerapan metode berbasis pelatihan statistik dan teknik optimasi matematis. Biodiesel bahan bakar diperoleh dari minyak kanola dengan metanol (MK), minyak jagung dengan metanol (MZ), minyak kanola dengan etanol (EK) dan minyak jagung dengan etanol (EZ) serta bahan bakar gabungan (EK \& MZ) dicampur dengan persentase volume yang berbeda $(2,5,10,20,80$ dan 100) dari solar minyak bumi. Pengumpulan data dilakukan dengan aplikasi hidung elektronik dilengkapi dengan 8 sensor metal oxide semiconductor (MOS). Analisis data dilakukan dengan menggunakan metode yang berbeda termasuk analisis diskriminan linier dan kuadratik (LDA dan DDA) serta dukunganmesin vektor (SVM). Berdasarkan hasil, SVM, QDA dan LDA memiliki presisi klasifikasi $94,8 \%, 94,1 \%$. dan $87,1 \%$. Selain itu, diskriminasi dan ketepatan klasifikasi SVM lebih tinggi (sekitar 95,4\%) untuk dua kelompok bahan bakar murni dan tidak murni (berbagai campuran solar dan biodiesel). Untuk QDA dan LDA metode, nilai presisi ini masing-masing $84,4 \%$ dan $75,5 \%$. Klasifikasi bahan bakar B5 lebih baik di semua metode jika dibandingkan dengan bahan bakar B2 dan B20. Deteksi dan ketepatan klasifikasi biodiesel B5 adalah 100\%, 97.6\% dan $96.1 \%$ untuk metode LDA, QDA dan SVM. Penerapan keinginan keseluruhan Fungsi ini menunjukkan bahwa metode QDA memiliki kinerja yang lebih baik jika dibandingkan dengan LDA dan SVM karena lebih tinggi diskriminasi dan kemampuan klasifikasi. Parameter kinerja model ini adalah 0,941, $0,941,0,975$ dan 0,850 untuk presisi ratarata, sensitivitas, spesifisitas dan keinginan akhir, masing-masing[3].

Penelitian yang dilakukan oleh Korosh Mahmodi, dalam artikelnya yang berjudul "Analisis Sentimen Data Presiden Jokowi Dengan Preprocessing Normalisasi Dan Stemming Menggunakan Metode Naive Bayes Dan SVM“ menyimpulkan bahwa akurasi yang terbaik dalam penelitian ini dengan dilakukan normalisasi dan stemming pada data sebesar 89,2655\% menggunakan metode SVM, dan kemudian data yang dinormalisasi saja sebesar $88,7006 \%$ menggunakan metode SVM. Dalam penelitian ini, tidak ada ujicoba terhadap data yang dilakukan stemming saja, dikarenakan tahap yang harus 
DOI : 10.29408/jit.v4i1.2961 Link : https://dx.doi.org/10.29408/jit.v4i1.2961

dilakukan dalam stemming adalah melakukan normalisasi terlebih dahulu terhadap data[5].

\subsection{Landasan Teori}

\section{Data Mining}

Data Mining adalah sebuah proses percarian secara otomatis informasi yang berguna dalam tempat penyimpanan data berukuran besar. Pengertian lain dari data mining adalah bagian integral dari knowledge discovery in databases $(K D D)$. Istilah lain yang sering digunakan diantaranya knowledge discovery (mining) in databases (KDD), knowledge extraction, data analysis, data archeology, data dredging, information harvesting, dan business intelligence. Salah satu teknik yang dibuat dalam data mining adalah bagaimana menelusuri data yang ada untuk membangun sebuah model, kemudian menggunakan model tersebut agar dapat mengenali pola data yang lain yang tidak berada dalam basis data yang tersimpan. Kebutuhan untuk prediksi juga dapat memanfaatkan teknik ini. Dalam data mining, pengelompokan data juga bisa dilakukan. Tujuannya adalah agar kita dapat mengetahui pola universal data-data yang ada.

\section{Algoritma-algoritma Data Mining.}

Berikut ini adalah algoritma-algoritma data mining yang digunakan untuk pengolahan berbagai jenis data, yaitu :

\section{a. K-Means}

K-means merupakan salah satu metode clusteringnon hirarki yang berusaha mempartisi data yang ada ke dalam bentuk satu atau lebih cluster. Metode ini mempartisi data ke dalam cluster sehingga data yang memiliki karakteristik yang sama dikelompokkan ke dalam satu cluster yang sama dan data yang mempunyai karateristik yang berbeda dikelompokan ke dalam cluster yang lain[6].

b. Support Vector Machine

SVM adalah metode machine learning yang bekerja dengan tujuan menemukan hyperplane terbaik yang memisahkan dua buah class pada input space. SVM merupakan sistem pembelajaran yang menggunakan ruang hipotesis berupa fungsi-fungsi linier dalam sebuah ruang fitur (feature space) berdimensi tinggi, dilatih dengan algoritma pembelajaran yang didasarkan pada teori optimasi dengan mengimplementasikan learning yang berasal dari teori pembelajaran statistik.

c. C 4.5

Pohon Keputusan (Decision Tree) merupakan metode klasifikasi dan prediksi yang sangat kuat dan terkenal. Pohon keputusan juga berguna untuk mengeksplorasi data, menemukan hubungan tersembunyi antara sejumlah calon variabel input dengan sebuah variabel target. karena pohon keputusan memadukan antara eksplorasi data dan 
DOI : 10.29408/jit.v4i1.2961 Link : https://dx.doi.org/10.29408/jit.v4i1.2961

pemodelan, pohon keputusan ini sangat bagus sebagai langkah awal dalam proses pemodelan bahkan ketika dijadikan sebagai model akhir dari beberapa teknik lain[7].

d. Apriori

Algoritma apriori adalah sebuah algoritma pencarian pola yang sangat populer dalam teknik penambangan data (data mining).

e. Naive Bayes

Naive Bayes merupakan pengklasifikasian dengan metode probabilitas dan statistik yang dikemukakan oleh ilmuwan Inggris Thomas Bayes, yaitu memprediksi peluang di masa depan berdasarkan pengalaman di masa sebelumnya sehingga dikenal sebagai teorema bayes ${ }^{[8][9] .}$

\section{f. K-Nearest Neighbor}

K-Nearest Neighbor (KNN) adalah suatu metode yang menggunakan algoritma supervised dimana hasil dari query instance yang baru diklasifikan berdasarkan mayoritas dari kategori pada K-Nearest Neighbor. Algoritma metode K-Nearest Neighbor sangatlah sederhana, bekerja berdasarkan jarak terpendek dari queryinstance ke training sample untuk menentukan K-Nearest Neighbor-nya. Training sample diproyeksikan ke ruang berdimensi banyak, dimana masingmasing dimensi merepresentasikan fitur dari data. Ruang ini dibagi menjadi bagian-bagian berdasarkan klasifikasi training sample ${ }^{[10]}$.

\section{Metode Penelitian}

Untuk mendapatkan informasi yang dibutuhkan serta jelas, penulisan dilakukan dengan cara :

1. Observasi

Dilakukan dengan mengumpulkan data dari mengamati secara langsung di lokasi penelitian yaitu masyarakat kecamatan selong yang diambil secara random.

\section{Wawancara}

Melakukan tanya jawab dengan masyarakat Kecamatan Selong menggunakan lembar interview yang dimasukkan ke dalam system yaitu aplikasi KKN Tematik Desa Gemilang tahun 2019.

3. Studi Pustaka

Pengumpulan informasi yang dibutuhkan dilakukan dengan mencari referensi-referensi yang berkaitan dengan kasus yang dibahas melalui buku dan internet.

\section{Tahapan Penelitian}

Pengolahan dilakukan menggunakan 4 kali eksperimen pada tiap-tiap algoritma, dengan mengacu pada $4 \mathrm{~K}$-Vold Validation yaitu : KVold Validation 7, K-Vold Validation 8, K-Vold Validation 9 danK-Vold Validation 10.

a) Pengertian Pengolahan data dengan menggunakan komputer terkenal dengan nama Pengolahan Data Elektronik (PDE) atau Electronik Data Processing (EDP). Pengolahan data (data processing) adalah manipulasi dari data ke dalam bentuk yang 
DOI : 10.29408/jit.v4i1.2961 Link : https://dx.doi.org/10.29408/jit.v4i1.2961

lebih berguna dan lebih berarti, berupa suatu informasi.

b) Siklus Pengolahan Data

Suatu proses pengolahan data terdiri dari 3 tahapan dasar, yang disebut dengan siklus pengolahan data (data processing cycle), yaitu input, processing dan output (Hartono, 1999).

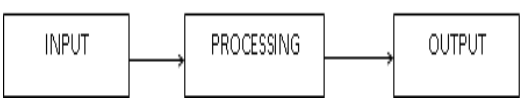

Tiga tahap dasar dari siklus pengolahan data tersebut dapat dikembangkan lebih lanjut. Siklus pengolahan data yang dikembangkan dapat ditambahkan tiga atau lebih tahapan lagi, yaitu origination, storage dan distribution.

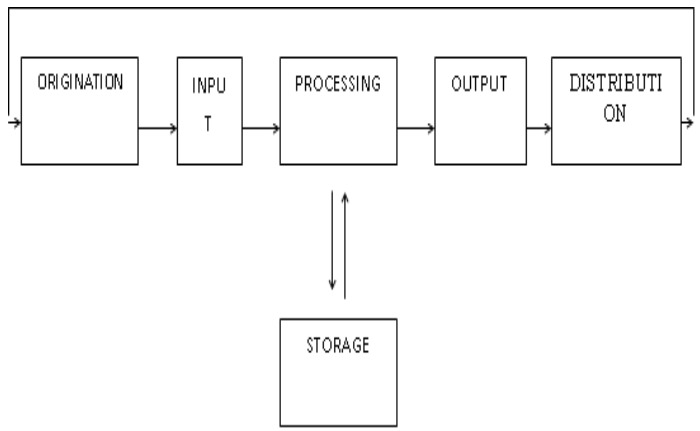

c) Origination.

Tahap ini berhubungan dengan proses dari pengumpulan data yang biasanya merupakan proses pencatatan (recording) data ke dokumen dasar.

d) Input.

Tahap ini merupakan proses memasukkan data ke dalam komputer lewat alat input (input device). Tahapan ini meliputi kegiatan : Collecting, Veryfing, Encoding. e) Processing.

Tahap ini merupakan proses pengolahan dari data yang sudah dimasukkan yang dilakukan oleh alat pemroses (processing device), yang dapat berupa proses menghitung, membandingkan, mengklasifikasikan, mengurutkan, mengendalikan atau mencari di storage. Tahapan ini meliputi kegiatan : Classifying, Sorting, Calculating, Sumarizing

f) Output.

Tahap ini merupakan proses menghasilkan output/keluaran dari hasil pengolahan data ke alat output (output device), yaitu berupa informasi. Tahapan ini meliputi kegiatan: Storing, Retrieving, Communication, Reproducing.

g) Distribution.

Tahap ini merupakan proses dari distribusi output kepada pihak yang berhak dan membutuhkan informasi.

h) Storage.

Tahap ini merupakan proses perekaman hasil pengolahan ke simpanan luar (storage). Hasil dari pengolahan yang disimpan di storage dapat dipergunakan sebagai bahan input untuk proses selanjutnya. 
DOI : 10.29408/jit.v4i1.2961 Link : https://dx.doi.org/10.29408/jit.v4i1.2961

\section{Hasil Analisis dan Pembahasan}

Hasil eksperimen memberikan informasi antara lain :

- Nilai akurasi yang ditunjukkan oleh algoritma Naive Bayes cenderung berubahubah baik dilihat dari nilai akurasi maupun nilai toleransinya, sedangkan apabila menggunakan algoritma Support Vector Machine nilai akurasi cenderung tetap, hanya toleransi yang berubah-ubah, namun tidak terlalu signifikan.

- Nilai akurasi yang tertinggi ditunjukkan oleh eksperimen menggunakan K-Vold Validation 8 dan K-Vold Validation 10. Sedangkan toleransi yang diberikan pada K-Vold Validation $8(0.49 \%)$ lebih kecil dari $\mathrm{K}=$ Vold Validation 10 sebesar $(0.58 \%)$. Hal ini berarti K-Vold Validation 8 lebih ketat dari K-Vold Validation 10. Sehingga yang paling baik digunakan dalam pegambilan keputusan adalah K-Vold Validation 8 sebesar $99.62 \%$.

- Hasil pengolahan data menggunakan algoritma Naive Bayes dan Support Vector Machine, sama-sama memberikan gambaran bahwa pengaruh ekonomi terhadap tingkat kesejahteraan masyarakat Desa Suralaga sangat besar dan memberikan gambaran bahwa rata-rata masyarakat Desa Suralaga termasuk dalam kategori masyarakat yang tidak sejahtera dengan tingkat akurasi $99.62 \%$.

\section{Kesimpulan}

Berdasarkan hasil penelitian yang telah dilakukan, Nilai akurasi yang tertinggi ditunjukkan oleh eksperimen menggunakan KVold Validation 8 dan K-Vold Validation 10. Sedangkan toleransi yang diberikan pada KVold Validation 8 (0.49\%) lebih kecil dari $K=$ Vold Validation 10 sebesar $(0.58 \%)$. Hal ini berarti K-Vold Validation 8 lebih ketat dari KVold Validation 10. Sehingga yang paling baik digunakan dalam pegambilan keputusan adalah K-Vold Validation 8 sebesar $99.62 \%$ dengan toleransi $0.49 \%$. Hasil pengolahan data menggunakan algoritma Naive Bayes dan Support Vector Machine.

\section{DaftarPustaka}

[1] K. A. K. Niazi, W. Akhtar, H. A. Khan, Y. Yang, and S. Athar, "Hotspot diagnosis for solar photovoltaic modules using a Naive Bayes classifier," Sol. Energy, vol. 190, no. August, pp. 34-43, 2019, doi: 10.1016/j.solener.2019.07.063.

[2] S. Niell et al., "Beehives biomonitor pesticides in agroecosystems: Simple chemical and biological indicators evaluation using Support Vector Machines (SVM)," Ecol. Indic., vol. 91, no. January, 
DOI : 10.29408/jit.v4i1.2961 Link : https://dx.doi.org/10.29408/jit.v4i1.2961

pp. 149-154, 2018, doi: 10.1016/j.ecolind.2018.03.028.

[3] K. Mahmodi, M. Mostafaei, and E. MirzaeeGhaleh, "Detection and classification of diesel-biodiesel blends by LDA, QDA and SVM approaches using an electronic nose," Fuel, vol. 258, no. May, p. 116114, 2019, doi: 10.1016/j.fuel.2019.116114.

[4] andi nurul Hidayat, "Analisis Sentimen Terhadap Wacana Politik Pada Media Masa Online Menggunakan Algoritma Support Vector Machine Dan Naive Bayes," J. Elektron. Sistim Inf. Dan Komput., vol. 1, no. 1, pp. 1-7, 2015.

[5] N. Saputra, T. B. Adji, and A. E. Permanasari, "Analisis Sentimen Data Presiden Jokowi dengan Preprocessing Normalisasi dan Stemming Menggunakan Metode Naive Bayes dan SVM," J. Din. Inform., vol. 5, no. November, p. 12, 2015, [Online]. Available: http://ojs.upy.ac.id/ojs/index. php/dinf/article /view/113.

[6] mahpuz Yahya, "Penggunaan Algoritma KMeans Untuk Menganalisis Pelanggan Potensial Pada Dealer SPS Motor Honda Lombok Timur Nusa Tenggara Barat," Infotek, vol. 2, no. 2, p. 373426, 2019.

[7] reni zuliana Yahya, "Prediksi Jumlah Penggunaan BBM Perbulan Menggunakan Algoritma Decition Tree (C4.5) Pada
Kantor Dinas Lingkungan Hidup dan Kebersihan Kecamatan Selong Kabupaten Lombok Timur," vol. 1, no. 1, pp. 430-439, 2018.

[8] Y. H. Hui et al., "PENERAPAN ALGORITMA NAIVE BAYES UNTUK MEMPREDIKSI JUMLAH PRODUKSI BARANG BERDASARKAN DATA PERSEDIAAN DAN JUMLAH PEMESANAN PADA CV. PAPADAN MAMA PASTRIES. Volume 1.," J. Mantik Penusa, vol. 1, no. 2, pp. 16-21, 2017, [Online].

Available: https://ezp.lib.unimelb.edu.au/login?url=htt ps://search.ebscohost.com/login.aspx?dire $c t=t r u e \& d b=f f h \& A N=2008-10-$ Aa4022\&site=eds-live\&scope=site .

[9] muhammad wasil mahpuz, yahya, "Implementasi Algoritma Decision Tree Untuk Mengetahui Faktor Kredit Macet Dan Lancar di Koperasi Serba Usaha Daruzzakah Rensing Lombok Timur," Infotek, vol. 3, no. 2, pp. 9-20, 2020.

[10] W. P. H. Yahya, "Penerapan Algoritma KNearest Neighbor Untuk Klasifikasi Efektivitas Penjualan Vape ( Rokok Elektrik ) pada ' Lombok Vape On ' Pendahuluan dihasilkan tidak stabil dan tidak mampu diprediksi Dari penelitian yang dilakukan , berusaha untuk mengklasifikasika," Infotek, vol. 3, no. 2, pp. 21-31, 2020. 
DOI : 10.29408/jit.v4i1.2961 Link : https://dx.doi.org/10.29408/jit.v4i1.2961

[11] Y. A. Setianto, K. Kusrini, and H. Henderi, "Penerapan Algoritma K-Nearest Neighbour Dalam Menentukan Pembinaan Koperasi Kabupaten Kotawaringin Timur," Creat. Inf. Technol. J., vol. 5, no. 3, p. 232, 2019, doi: 10.24076/citec.2018v5i3.179. 